\title{
Insulin and glucagon in spontaneously diabetic non-obese mice
}

\author{
A. Ohneda, T. Kobayashi, J. Nihei, Y. Tochino, H. Kanaya and S. Makino \\ Third Department of Internal Medicine, Tohoku University School of Medicine, Sendai and Shionogi Research Laboratory, Shionogi \& Co, \\ Osaka, Japan
}

\begin{abstract}
Summary. To investigate the rôle of glucagon in the development of diabetes mellitus, spontaneously diabetic non-obese mice were studied before (group 1) and after the onset of diabetes mellitus (group 2). In group 1, fasting blood glucose and insulin in plasma and pancreas did not differ significantly, while plasma glucagon was elevated $(48.9 \pm 10.4$ versus control $18.6 \pm 6.0 \mathrm{pmol} / 1)$. In group 2 , the insulin content of plasma and the pancreas were markedly reduced, whereas plasma glucagon was elevated $(180.9 \pm 59.1 \mathrm{pmol} / 1)$. When diabetic mice were treated with insulin for 4 weeks (group 3), plasma glucagon was markedly reduced compared with that of
\end{abstract}

group $2(30.3 \pm 9.0 \mathrm{pmol} / 1)$. In group 1 , glucagon and glucagon-like immunoreactivity of the intestine were reduced. The glucagon content of the intestine was elevated in group 2 . Group 3 elicited increased contents of gastric glucagon as well as intestinal glucagon-like immunoreactivity. We conclude that, in addition to insulin deficiency, hypersecretion of glucagon might contribute to the development and clinical course of diabetes mellitus in the non-obese diabetic mouse.

Key words: Non-obese diabetic mice, pancreas, stomach, insulin, glucagon, intestine.
Although the rôle of glucagon in pathophysiology of diabetes mellitus has been suggested [1], it's effect on the development of diabetes mellitus in man is still obscure. Since there have been many difficulties in studying changing A-cell function of the pancreatic islets over a long period of time in human diabetes, spontaneously diabetic animals have been investigated. Most authors deal with glucagon secretion in animals which are characterized by obesity, hyperglycaemia and hyperinsulinaemia [2-5]. In contrast, a few studies report the presence of glucagon in plasma and the pancreas of diabetic animals with ketosis [6-9]. Recently, spontaneously diabetic mice have been described which revealed a decrease in body weight, sudden onset of diabetes, insulitis and insulin deficiency, and have been named nonobese diabetic mice (NOD) [10]. Previous experimental studies indicate that NOD mice could be regarded as a model for Type 1 (insulin-dependent) diabetes in man [10]. Therefore, the present study was performed using NOD mice to investigate changes in insulin and glucagon levels in the development of diabetes.

\section{Materials and methods}

\section{Animals}

Spontaneously NOD female mice were used from the ICR strain at the Shionogi Laboratory, Shiga, Japan. The animals were fed a commercial diet CA-1 ad libitum (Clea Japan Inc., Tokyo, Japan). To investigate the changes in pancreatic islet function, the experimental animals were divided into three groups: mice before development of diabetes ( $n=14$, group 1 , aged approximately 60 days), and mice with overt diabetes at the age of 120 days $(n=10$, group 2$)$. Furthermore, to see the effect of insulin treatment, diabetic mice aged approximately 140 days were administered insulin (MC monotard insulin, Novo Institute, Denmark) at a daily dose of $40 \mathrm{U} / \mathrm{kg}$ of body weight for 4 weeks ( $n=7$, group 3 ). Ten female ICR mice aged 60,120 and 150 days served as the three control groups. In group 3, experiments were performed approximately $20 \mathrm{~h}$ after the last injection of insulin. All the animals were anaesthetized with an intraperitoneal injection of Nembutal $(6 \mathrm{mg} / 100 \mathrm{~g}$ body weight) after an overnight fast, and blood was obtained from the inferior vena cava with a heparinized sym ringe. After exsanguination, the pancreas, stomach and small intestine were removed, frozen immediately and kept at $-20^{\circ} \mathrm{C}$ until extraction of hormones.

\section{Methods}

Blood glucose was determined by the glucose oxidase method, using the blood sugar-GOD-Perid test (Boehringer, Mannheim, FRG). For the measurement of hormones, blood samples were collected in glass tubes containing aprotinin $(500 \mathrm{U} / \mathrm{ml}$ blood, Trasylol, Bayer, Leverkusen, FRG), and plasma was separated by centrifugation ( $1500 \mathrm{~g}$ at $4^{\circ} \mathrm{C}$ ). Plasma was kept at $-20^{\circ} \mathrm{C}$ until assayed. Plasma insulin (IRI) was determined by the method of Morgan and Lazarow [11]. Pork crystalline insulin was used as a standard. Glucagon was measured by radioimmunoassay using both C-terminal specific (G21) and nonspecific antiserum $(\mathrm{G} 25)$, as described elsewhere $[12,13]$. In this study, glucagon measured by specific antiserum was designated as immunoreactive glucagon (IRG), and by non-specific antiserum as glucagonlike immunoreactivity. Insulin and glucagon were extracted from the pancreas, stomach and small intestine according to the method of Kenny [14].

\section{Statistical analyses}

Statistical analysis was performed using the two-tailed Student's t-test. 


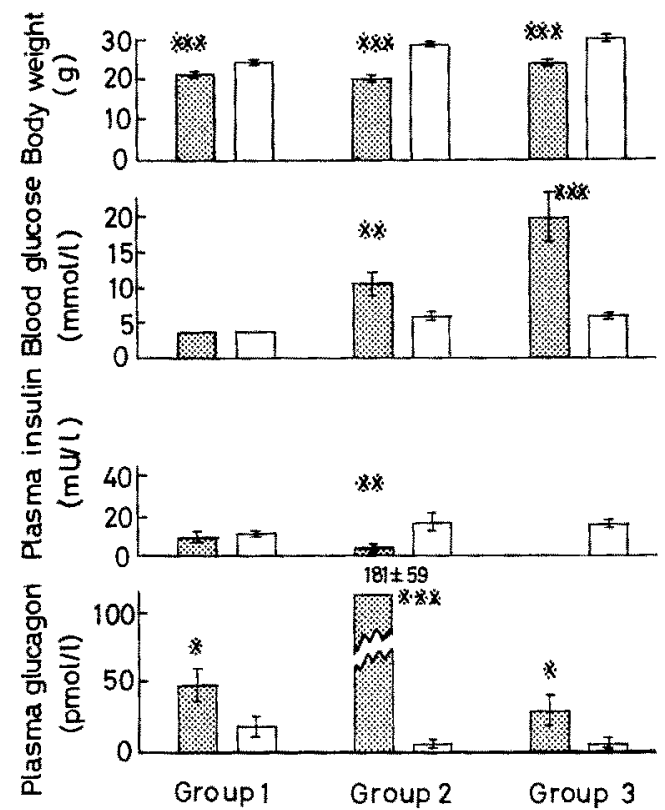

Fig. 1. Body weight, blood glucose, plasma insulin and glucagon levels in NOD (영) and control mice (). Group 1 consisted of 14 NOD and 10 control mice, group 2, 10 mice from each group and group 3 , seven NOD and 10 control mice. $* p<0.05 ; * *<<0.01$ and $* * x<$ 0.001 versus respective control groups

\section{Results}

\section{Body weight}

The mice in groups 1 and 2 weighed less than in their control groups $(21.4 \pm 0.2$ and $20.7 \pm 1.0 \mathrm{~g}$ versus $24.4 \pm 0.2$ and $28.9 \pm 0.2 \mathrm{~g}, p<0.001$; Fig. 1). Insulin treatment increased body weight slightly (group 3 ), but this was still lower than that of the control group $(24.3 \pm 0.7$ versus $30.4 \pm 0.2 \mathrm{~g}, p<0.001)$.

\section{Blood glucose}

In group 2 blood glucose levels were elevated (10.5 \pm $1.6 \mathrm{mmol} / 1, p<0.01$ ), while in group 1 they remained within the normal range (Fig. 1). In spite of insulin treatment, blood glucose levels were still elevated in group 3 $(19.5 \pm 3.1 \mathrm{mmol} / 1, p<0.001)$.

\section{Plasma IRI and IRG}

The mean fasting plasma IRI level in group 1 was $9.6 \pm 2.0 \mathrm{mU} / 1$, indicating no significant difference from the control mice $(10.9 \pm 0.8 \mathrm{mU} / 1)$. However, mean plasma IRI in group 2 was markedly reduced $(4.6 \pm 0.6 \mathrm{mU} / 1, p<0.01)$. Plasma IRI was not measured in group 3 because of possible circulating insulin antibodies. The fasting levels of plasma IRG were elevated in group 1 compared with the control group $(48.9 \pm 10.4$ versus $18.6 \pm 6.0 \mathrm{pmol} / 1, p<0.05$ ). Furthermore, plasma IRG in group 2 was prominently increased compared with the control group (180.9 \pm 59.1 versus $8.0 \pm$ $2.7 \mathrm{pmol} / 1, p<0.001)$. After insulin treatment, plasma IRG was lowered in group 3, but the plasma IRG was still higher than that of the control mice $(30.3 \pm 0.9$ versus $7.6 \pm 3.9 \mathrm{pmol} / \mathrm{l}, p<0.05$ ).
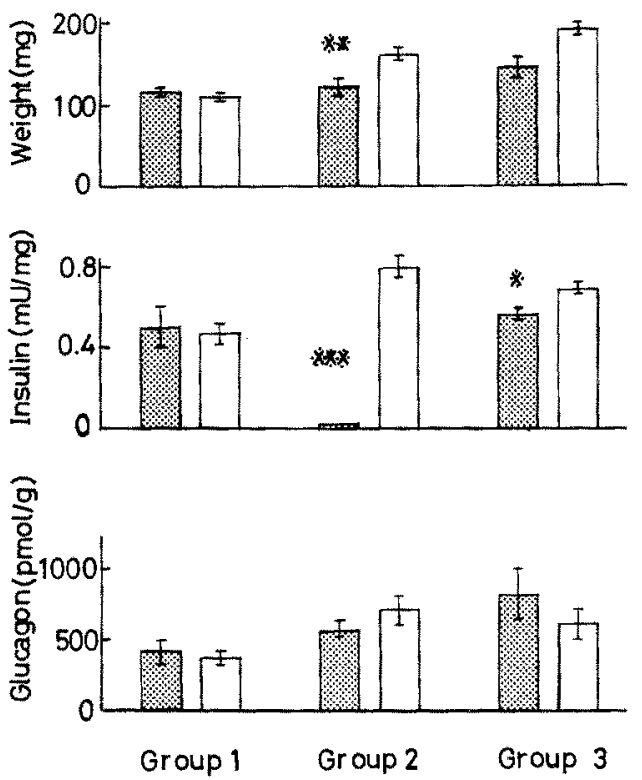

Fig. 2. Weight of pancreas and its contents of insulin and glucagon in NOD (争) and control mice ( $\square$ ). See legend to Figure 1 for number of mice in each group. * $p<0.05, * * p<0.01$ and $* * *<<0.001$ versus respective control groups

\section{Hormone in tissues}

There was no difference between the weight of the pancreas in group 1 and its control group (117.4 \pm 4.5 versus $113.9 \pm 5.9 \mathrm{mg}$ ). In contrast, the weight of the pancreas was markedly diminished in group 2 compared with its control group (121.6 \pm 10.6 versus $162.7 \pm 7.9 \mathrm{mg}, p<$ $0.01)$. However, in group 3 the weight of the pancreas increased after insulin treatment and there was no statistical difference in the weight of these pancreases and those in the control group $(164.9 \pm 12.1$ versus $191.0 \pm$ $8.6 \mathrm{mg}$; Fig. 2).

The changes in insulin content of the pancreas were parallel to those in the weight of the pancreas (Fig. 2). The insulin content did not differ in group $1(0.499 \pm$ $0.103 \mathrm{mU} / \mathrm{mg}$ ), but was markedly reduced in group 2 $(0.006 \pm 0.0018 \mathrm{mU} / \mathrm{mg}, p<0.001)$ compared with control groups. After insulin treatment (group 3), insulin content increased but was still lower than that of the control group $(0.575 \pm 0.034$ versus $0.681 \pm 0.029 \mathrm{mU} /$ $\mathrm{mg}, p<0.05$ ). A similar tendency was observed in the difference of the total insulin content of the pancreas (data not shown).

In contrast, the glucagon content of the pancreas in the experimental groups did not differ significantly from that of the control groups (Fig. 2). The total glucagon content of the pancreas did not differ in groups 1 and 3 , while it was significantly reduced in group 2 compared with its control group $(65.4 \pm 5.8$ versus $112 \pm 14.5 \mathrm{pmol} /$ total pancreas, $p<0.02$ ).

In general, smaller amounts of glucagon were observed in the stomach and intestine (Fig. 3). Gastric IRG in groups 1 and 2 did not differ from that of the control groups but was significantly increased in group 3 $(20.5 \pm 3.0$ versus control group $4.8 \pm 1.2 \mathrm{pmol} / \mathrm{g}, p<$ 

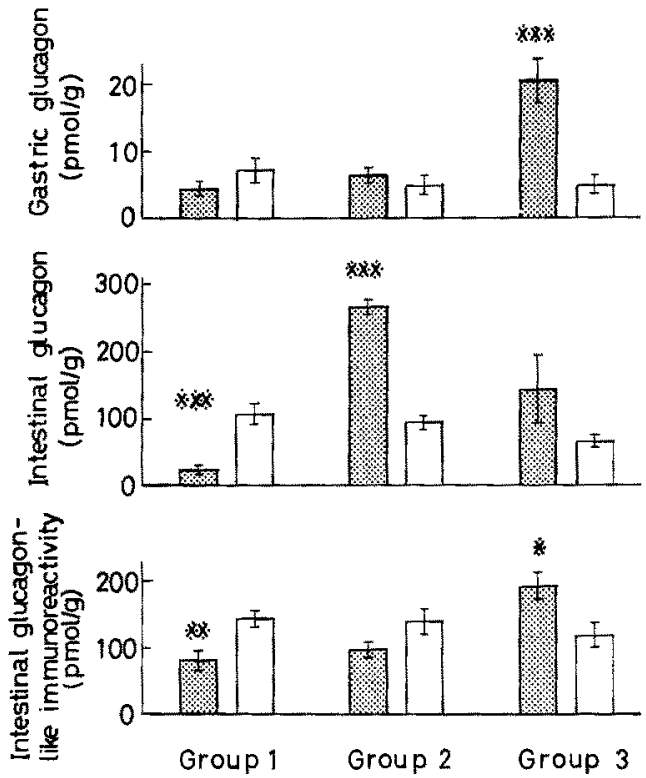

Fig.3. Tissue glucagon and glucagon-like immunoreactivity in NOD (응 and control mice ( $\square$ ). See legend to Figure 1 for number of mice in each group. $* p<0.05, * 0<0.01$ and $* * 0.001$ versus respective control groups

$0.001)$. The IRG content of the intestine in group 1 was reduced but after the onset of diabetes it increased, averaging $266.3 \pm 10.3 \mathrm{pmol} / \mathrm{g}$ in group 2 and $142.3 \pm$ $49.1 \mathrm{pmol} / \mathrm{g}$ in group 3 . The glucagon-like immunoreactivity content of the intestine was reduced in group 1 but did not reveal any differences between group 2 and the control group. In group 3, however, glucagon-like immunoreactivity content was slightly increased compared with that of the control group $(193.4 \pm 22.0$ versus $118.5 \pm 21.3 \mathrm{pmol} / \mathrm{g}, p<0.05)$.

\section{Discussion}

NOD mice were separated [10] from the CTS strain mice which in turn were derived from JCR-ICR mice and characterized by cataract with micro-ophthalmia [15]. According to previous studies, NOD mice revealed sudden onset of diabetes associated with marked loss of body weight, insulitis and insulin deficiency $[10,16]$. Therefore, NOD mice can be classified into spontaneously diabetic animals with ketosis. Biochemical findings of NOD mice resemble in part those of the BB rat $[6,7,17]$ and the diabetic Chinese hamster [8].

In the study of spontaneously diabetic animals, it is necessary to use appropriate control animals. In the case of NOD mice, another strain of the CTS strain [10] or littermates which do not develop overt diabetes might be a reasonable control. However, they were not available in the present study and age-matched female ICR mice were studied as control groups.

The present study demonstrates an increased fasting blood glucose and a low level of plasma insulin in group 2. The finding that the insulin content of the pancreas was markedly diminished in group 2 is consistent with the clinical course of NOD mice and confirms previous findings [10]. In contrast, there were no significant differences in fasting blood glucose or plasma insulin between group 1 and its control group. According to histological studies of NOD mice, lymphocytic infiltration in the pancreatic islet (insulitis) has been observed at 5 weeks of age $[10,16]$. Therefore, the pancreatic islets of the mice in group 1 are presumed to show such changes, because more than $60 \%$ of this strain develop overt diabetes [10].

Nevertheless, the plasma level and pancreatic content of insulin in group 1 did not differ significantly from control mice. Recent studies indicated that lymphocytic infiltration into the pancreatic islet occurs at 4 weeks of the age, increasing gradually and reaching the final stage, when overt diabetes occurs [18]. Therefore, the results obtained in the present study, coupled with morphological observations, suggest that only lesions of long duration and severity in the islet could lead to the development of diabetes mellitus.

In contrast, plasma glucagon increased in both groups 1 and 2. In a preliminary study, NOD mice revealed less suppressibility of plasma glucagon to hyperglycaemia and a slight increase in plasma glucagon response to arginine [19]. The changes observed in group 2 were similar to those in the BB rat $[6,20]$. Insulin treatment for 4 weeks reduced plasma glucagon, which was still higher than that of the control group. These changes in plasma glucagon after treatment with insulin are already recognized in human diabetes [12]. From clinical observation, the elevated response of plasma glucagon has been attributed to insulin deficiency [21] or diabetic metabolic derangement [12]. Therefore, elevated plasma glucagon observed in group 2 might be accounted for as a consequence of the diabetic state. The glucagon concentration in the pancreas of mice from group 2 did not differ from that in group 1, although the total glucagon content was reduced in group 2 compared with its control group. According to Fujita et al. [18], however, electron microscopic examination of NOD mice revealed an increased function of the A cell of the pancreatic islet in an overt diabetic group. Therefore, it seems possible that glucagon is secreted from the A cell much more in group 2. In addition, glucagon in the gut has recently been designated as extrapancreatic glucagon [22, 23], and was demonstrated to increase in the diabetic state [24]. Indeed, the glucagon content of the stomach was increased in group 3 and that of the intestine was increased in group 2, compared with the control groups. Therefore, it is also likely that increased plasma glucagon observed in groups 2 and 3 derives from the stomach and intestine.

The present study also demonstrated an increase in plasma glucagon in group 1. Group 1 did not elicit any hyperglycaemia or a decrease of plasma insulin. Therefore, the increase of plasma glucagon in group 1 cannot be attributed to metabolic derangement. The glucagon content of the pancreas in group 1 increased slightly, although not significantly. Furthermore, the glucagon content in the stomach and intestine was slightly decreased. The finding of pancreatic glucagon content is compatible with the morphological observation which 
elicits a decrease in the number of B cells but not A cells [18]. Therefore, an increase in plasma glucagon in group 1 could be interpreted as an increased biosynthesis of glucagon in the pancreatic islet, although a decreased degradation of glucagon in the tissues or a decreased uptake of glucagon in the target organs cannot be ruled out.

Recently one of the components of gut glucagonlike immunoreactive substance was purified and named glicentin [25]. It has been proposed that glicentin could be a precursor of glucagon [26]. However, the glucagonlike immunoreactivity in the intestine of groups 1 and 2 did not exceed that of the control groups, whereas it was noted to increase slightly in group 3 . This finding does not give support to the idea that glucagon is processed in the gut.

It has been reported that the onset of diabetes in NOD mice is abrupt and accompanied by insulitis with disappearance of $B$ cells $[10,16]$. Although the precise mechanism of islet destruction is unknown, hereditary factors, virus infection, the influence of sex hormone and immunological abnormalities have all been suggested $[10,16,27]$. The strain studied develops insulindeficiency diabetes, which has been used as a model for human Type 1 diabetes. In the present study, the plasma glucagon level was noted to increase even before the onset of overt diabetes as well as after the development of diabetes. Therefore, it can be concluded that, in addition to insulin deficiency, an enhancement of glucagon secretion might contribute to the development and progress of diabetes mellitus in NOD mice.

Acknowledgements.This study was supported in part by a Scientific Research Grant from the Ministry of Education, Science and Culture, Japan (No. 357206 and No.437048).

\section{References}

1. Unger RH (1978) Role of glucagon in the pathogenesis of diabetes. The status of controversy. Metabolism 27:1691-1709

2. Mahler RJ, Dubuc PU, Mobley PW, Ensinck JW (1976) Glucagon and insulin relationships in the obese hyperglycemic mouse (ob/ ob). Horm Metab Res 8: 79-80

3. Sterns SB, Benzo CA (1978) Glucagon and insulin relationships in genetically diabetic $(\mathrm{db} / \mathrm{db})$ and in streptozotocin-induced diabetic mice. Horm Metab Res 10: 20-23

4. Ohneda A, Kobayashi T, Nihei J, Nishikawa K. (1981) Glucagon in spontaneously diabetic KK mice. Horm Metab Res 13: 207-211

5. Leiter EH, Coleman DL, Eisenstein AB, Strack I (1980) A new mutation $\left(\mathrm{db}^{3 \mathrm{~J}}\right)$ at the diabetes locus in strain $129 / \mathrm{J}$ mice. I. Physiological and histological characterization. Diabetologia 19 . 58-65

6. Nakhooda AF, Like AA, Chappel CI, Murray FT, Marliss EB (1976) The spontaneously diabetic Wistar rat. Metabolism and morphologic studies. Diabetes 26: 100-112

7. Nakhooda AF, Like AA, Chappel CI, Wei C-N, Marliss EB (1978) The spontaneously diabetic Wistar rat (the "BB" rat). Studies prior to and during development of the overt syndrome. Diabetologia 14: $199-207$
8. Chang AY, Nobel RE, Wyse BM (1977) Comparison of highly inbred diabetic and non-diabetic lines in the Upjohn Colony of Chinese hamster. Diabetes 26: 1063-1701

9. Herberg L (1979) Spontaneously hyperglycemic laboratory animals - Model of human diabetes syndrome? Horm Metab Res 11: 323-331

10. Makino S, Kunimoto K, Muraoka Y, Mizushima Y, Katagiri K, Tochino Y (1980) Breeding of a non-obese, diabetic strain mice. Exp Animal 29: 1-13

11. Morgan CR, Lazarow A (1963) Immunoassay of insulin: two antibody system. Diabetes 12: 115-126

12. Ohneda A, Ishii S, Horigome K, Yamagata S (1975) Glucagon response to arginine after treatment of diabetes mellitus. Diabetes 24: 811-819

13. Ohneda A, Nihei $J$, Kobayashi T, Umezu M, Sakai T, Sanoyama K (1979) Effect of insulin treatment upon response of extrapancreatic glucagon to arginine. Tohoku J Exp Med 129: 207-217

14. Kenny AJ (1955) Extractable glucagon of human pancreas. J Clin Endocrinol Metab 15: 1089-1105

15. Ohotori H, Yoshida T (1968) Small eye and cataract, a new mutation in the mouse. Exp Animal 17:91-96

16. Tochino Y (1979) A new type of non-obese diabetic mouse accompanied with sudden onset and insulitis. Saishin Igaku 34: 1182-1188 (Japanese)

17. Marliss EB, Nakhooda AF, Poussier P (1983) Clinical forms and natural history of the diabetic syndrome and insulin and glucagon secretion in the BB rat. Metabolism 32 (Suppl 1): 11-17

18. Fujita T, Yui R, Kusumoto Y, Serizawa Y, Makino S, Tochino Y (1982) Lymphocytic insulitis in a 'non-obese diabetic (NOD)' strain of mice: an immunohistochemical and electron microscope investigation. Biomed Res 3: 429-443

19. Ohneda A, Kobayashi T, Nihei J, Tochino Y, Kanaya H, Makino $S$ (1981) Secretion of glucagon in spontaneously diabetic NOD mice. J Jap Diabet Soc 24: 202 (Japanese)

20. Patel YC, Wheatley T, Malaisse-Lagae F, Orci L (1980) Elevated portal and peripheral blood concentration of immunoreactive somatostatin in spontaneously diabetic (BBL) Wistar rat. Suppression with insulin. Diabetes 29:757-761

21. Kawamori R, Shichiri M, Kikuchi M, Yamasaki Y, Abe H (1980) Perfect normalization of excessive glucagon response to intravenous arginine in human diabetes mellitus with the artificial betacell. Diabetes 29: 762-765

22. Vranic M, Pek S, Kawamori R (1974) Increased "glucagon immunoreactivity" in plasma of totally depancreatized dogs. Diabetes 23: 905-912

23. Matsuyama T, Foà PP (1974) Plasma glucose, insulin, pancreatic and enteroglucagon levels in normal and depancreatized dogs. Proc Soc Exper Biol Med 147: 97-102

24. Ohneda A, Kobayashi T, Nihei J, Umezu M, Sakai T, Sanoyama $\mathrm{K}$ (1979) Response of extrapancreatic glucagon to arginine in dogs. Tohoku J Exp Med 129: 45-54

25. Sundby F, Jacobsen H, Moody AJ (1976) Purification and characterization of a protein from porcine gut with glucagon-like immunoreactivity. Horm Met Res 8: 366-371

26. Moody AJ, Jacobsen H, Sundby F, Frandsen EK, Baetens D, Orci L (1977) Heterogeneity of gut glucagon-like immunoreactivity. In: Foà PP, Bajai JS, Foà NL (eds) Glucagon: its rolle in physiology and clinical medicine. Springer, Berlin, pp 129-135

27. Kataoka S, Satoh J, Fujiya H, Toyota T, Suzuki R, Itoh K, Kumagai $\mathrm{K}$ (1983) Immunologic aspects of the nonobese diabetic mouse. Abnormalities of cellular immunity. Diabetes 32: 247-253

Received: 9 February 1984

and in revised form: 13 August 1984

Dr. Akira Ohneda

Third Department of Internal Medicine

Tohoku University School of Medicine

Sendai

Japan 980 